\title{
Jaringan Syaraf Tiruan dalam Memprediksi Jumlah Pelanggan PT.Telkom Akses Area Sumbagut Menggunakan Metode Backpropagation
}

\author{
Reza Muhammad Riansah ${ }^{1}$, Rahmat W. Sembiring ${ }^{2}$, Zulaini Masruro ${ }^{3}$ \\ ${ }^{1}$ Mahasiswa Program Studi Teknik Informatika, STIKOM Tunas Bangsa, Pematangsiantar \\ ${ }^{2}$ Dosen Program Studi Teknik Informatika, STIKOM Tunas Bangsa, Pematangsiantar \\ 123Jln. Sudirman Blok A No. 1, 2 dan 3 Pematangsiantar, 21117 \\ email: r3zabatubara@gmail.com,rahmatws@yahoo.com, zulaini@amiktunasbangsa.ac.id
}

\begin{abstract}
The number of customers of a service company greatly affects the development and progress of the company. Likewise with the number of customers of PT. Telkom Access (PTTA) Sumbagut Area which has an increase in the number of customers every year. In this study, the author will make predictions aimed at knowing the number of customers at PT. Telkom Access (PTTA) Sumbagut Area using the backpropagation method. Backpropagation is one method of artificial neural networks that mimics the workings of human nerves. Research uses data obtained from the database of PT. Telkom Access Pematangsiantar. This study produced the best architectural model, namely 3-14-1 which will be used to predict the number of customers of PT. Telkom Access (PTTA) Sumbagut Area with 85\% accuracy.
\end{abstract}

Keywords: Predictions, Algorithms, Backpropagation, Customers.

Abstrak- Jumlah pelanggan suatu perusahaan jasa sangat mempengaruhi perkembangan dan kemajuan bagi perusahaan. Demikian dengan jumlah pelanggan PT. Telkom Akses (PTTA) Area Sumbagut yang mengalami kenaikan jumlah pelanggan setiap tahunnya. Pada penelitian ini, penulis akan melakukan prediksi yang bertujuan untuk mengetahui jumlah pelanggan pada PT. Telkom Akses (PTTA) Area Sumbagut dengan menggunakan metode backpropagation. Backpropagation merupakan salah satu metode jaringan syaraf tiruan yang meniru cara kerja syaraf manusia. Penelitian menggunakan data yang diperoleh dari database PT. Telkom Akses Pematangsiantar. Penelitian ini menghasilkan model arsitektur terbaik yaitu 3-14-1 yang akan digunakan untuk memprediksi jumlah pelanggan PT. Telkom Akses (PTTA) Area Sumbagut dengan keakurasian $85 \%$.

Kata Kunci: Prediksi, Algoritma, Backpropagation, Pelanggan.

\section{PENDAHULUAN}

Pelanggan PT. Telkom Akses (PTTA) dari tahun 2012 sampai dengan 2017 terus meningkat. Pelanggan adalah orang yang menjadi pembeli produk yang telah di buat dan dipasarkan oleh sebuah perusahaan, dimana orang ini bukan hanya sekali membeli produk tersebut tetapi berulang-ulang [1]. Dengan meningkatnya setiap tahun pelanggan PTTA maka prediksi pelanggan PTTA akan sangat berguna untuk perusahaan karena perusahaan akan selalu siap dalam menyediakan keperluan-keperluan permintaan pelanggan. 
Tabel 1.Sampel Data Pelanggan PT. Telkom Akses Area Sumbagut

\begin{tabular}{|c|c|c|c|c|c|c|c|c|c|c|c|}
\hline \multirow[t]{2}{*}{ No } & \multirow[t]{2}{*}{ Nama Kota } & \multicolumn{6}{|c|}{ Tahun } & \multirow[b]{2}{*}{2018} & \multirow[b]{2}{*}{2019} & \multirow[b]{2}{*}{2020} & \multirow[b]{2}{*}{2021} \\
\hline & & 2012 & 2013 & 2014 & 2015 & 2016 & 2017 & & & & \\
\hline 1 & Pematangsiantar & 57 & 83 & 121 & 169 & 197 & 257 & 261 & 275 & 293 & 327 \\
\hline 2 & Rambung Merah & 12 & 34 & 67 & 98 & 122 & 159 & 157 & 159 & 195 & 253 \\
\hline 3 & Pematang raya & 19 & 42 & 84 & 133 & 176 & 193 & 212 & 208 & 219 & 245 \\
\hline 4 & Sidamanik & 6 & 26 & 58 & 81 & 101 & 124 & 150 & 176 & 206 & 254 \\
\hline 5 & Seribudolok & 4 & 19 & 34 & 58 & 71 & 93 & 101 & 127 & 167 & 224 \\
\hline 6 & Parapat & 26 & 55 & 90 & 134 & 180 & 221 & 222 & 228 & 254 & 280 \\
\hline 7 & Serbelawan & 16 & 33 & 69 & 90 & 122 & 155 & 159 & 166 & 195 & 250 \\
\hline 8 & Perdagangan & 8 & 24 & 55 & 81 & 99 & 117 & 145 & 177 & 206 & 253 \\
\hline 9 & Kisaran & 17 & 30 & 51 & 89 & 102 & 129 & 139 & 176 & 216 & 249 \\
\hline 10 & Tanjung Balai & 9 & 29 & 47 & 59 & 82 & 101 & 117 & 139 & 191 & 244 \\
\hline
\end{tabular}

Prediksi merupakan sesuatu hal yang digunakan untuk mengetahui kejadian di masa yang akan datang dengan mengenali pola kejadian di masa lalu. Dengan mengetahui kejadian yang akan terjadi membuat setiap orang lebih mempersiapkan segala sesuatu, baik untuk kehidupan manusia maupun harta benda yang dimiliki [2]. Algortima yang dipakai dalam jaringan saraf tiruan untuk memprediksi ialah algortima backpropagation. Backpropagation merupakan salah satu dari metode pelatihan pada jaringan syaraf, dimana ciri dari metode ini adalah meminimalkan error pada output yang dihasilkan oleh jaringan [3]. Adapun penelitian terkait dengan jaringan syaraf tiruan backpropagation yaitu pada penelitian yang dilakukan I. Muzakir, A. Syukur \& I.N. Dewi (2014), melakukan penelitian Peningkatan akurasi algoritma backpropagation dengan seleksi fitur particle swarm optimization dalam prediksi pelanggan telekomunikasi yang hilang. Menggunakan Backpropagation menghasilkan tingkat akurasi sebesar 85,48\%. Sedangkan dengan menggunakan backpropagation berbasis particle swarm optimization menghasilkan tingkat akurasi sebesar 86,05\% [4].

\section{METODOLOGI PENELITIAN}

\subsection{Jaringan Saraf Tiruan Backpropagation}

Jaringan Saraf Tiruan (JST) Backpropagation (BP) merupakan ilmu matematika, yang sering digunakan untuk prediksi dan perkiraan waktu, yang juga menentukan hasil untuk fungsi non-linear. Algoritma backpropagation digunakan untuk latihan. Algoritma backpropagation adalah algoritma iteratif yang mudah dan sederhana yang biasanya berkinerja baik, bahkan dengan data yang kompleks [5]-[7]. Tidak seperti Algoritma pembelajaran lainnya (seperti pembelajaran Bayesian), backpropagation memiliki sifat komputasi yang baik apalagi bila data yang tersaji berskala besar. Metode pelatihan backpropagation melibatkan feedforward dari pola pelatihan input, perhitungan dan backpropagation dari kesalahan, dan penyesuaian bobot pada sinapsis [8]-[14]. Backpropagation melatih jaringan untuk mendapatkan keseimbangan antara kemampuan jaringan mengenali pola yang digunakan selama training serta kemampuan jaringan untuk memberikan respon yang benar terhadap pola masukan yang serupa tapi tidak sama dengan pola yang dipakai selama pelatihan [3]. 


\subsection{PT. Telkom Akses (PTTA)}

PT. Telkom Akses (PTTA) merupakan salah satu anak dari perusahaan Telkom yang bergerak di bidang konstruksi pembangunan dan manage service infrastruktur jaringan. PT. Tekom Akses (PTTA) didirikan pada tahun 12 Desember 2012. Pendirian PTTA merupakan bagian dari komitmen Telkom untuk terus melakukan pengembangan jaringan broadband untuk menghadirkan akses informasi dan komunikasi tanpa batas bagi seluruh masyarakat Indonesia [15].

\subsection{Pelanggan}

Pelanggan adalah orang yang menjadi pembeli produk yang sudah dibuat dan dipasarkan oleh sebuah perusahaan, dimana orang ini bukan hanya sekali membeli produk tersebut tetapi berulang-ulang [1].

\subsection{Prediksi}

Prediksi adalah usaha untuk memperkirakan sesuatu yang akan terjadi di masa mendatang dengan memanfaatkan berbagai informasi yang relevan pada waktu-waktu sebelumnya (historis) melalui suatu metode ilmiah. Tujuan dari prediksi adalah mendapatkan informasi apa yang akan terjadi di masa datang dengan probabilitas kejadian terbesar [16].

\subsection{Flowchart Metode Penelitian}

Flowchart yang digunakan dalam menyelesaikan masalah penelitian ini.

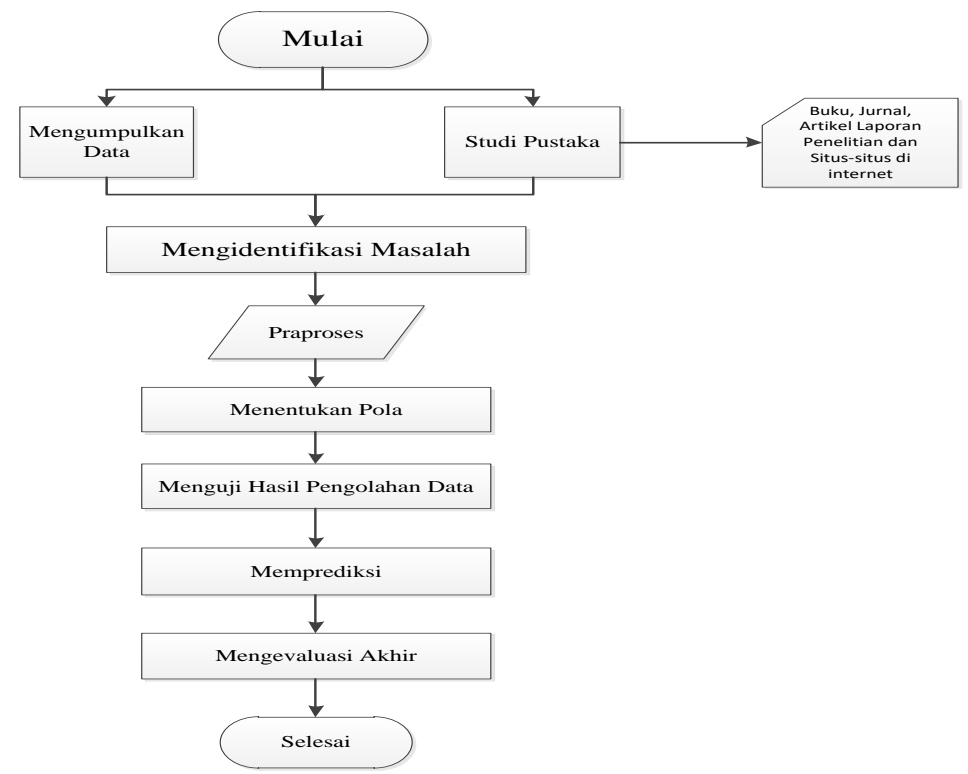

Gambar 1. Flowchart Metode Penelitian

Keterangan :

a. Mengumpulkan Data

Pada tahap ini, data-data yang digunakan diperoleh dari data jumlah pelanggan PT. Telkom Akses Area Sumbagut yang diambil dari dari database PT. Telkom Akses Pematangsiantar. 
b. Studi Pustaka

Studi pustaka merupakan langkah awal dalam penelitian ini, studi pustaka ini dilakukan untuk melengkapi pengetahuan dasar dan teori-teori yang digunakan berasal dari buku, jurnal, artikel laporan penelitian, dan situs-situs di internet.

c. Mengidentifikasi Masalah

Mengidentifikasi masalah ini dilakukan setelah semua data-data terpenuhi kemudian didapatkan dataset yang sesuai untuk dilakukan proses pada tahap konversi data yang didapat sesuai dengan bobot yang ditentukan.

d. Praproses

Tahapan ini melakukan perubahan terhadap beberapa tipe data pada atribut dataset dengan tujuan untuk mempermudah pemahaman terhadap isi record, juga melakukan seleksi dengan memperhatikan konsistensi data.

e. Menentukan Pola

Hasil dari tahap ini adalah beberapa model backpropagation untuk menentukan pola.

f. Menguji Hasil Pengolahan Data

Setelah selesai melakukan proses penentuan model, maka dilakukan tahap uji coba terhadap hasil pengolahan data dengan menggunakan software Matlab R2011b.

g. Memprediksi

Prediksi dilakukan untuk membandingkan jumlah dengan model algoritma backpropagation yang paling akurat.

h. Mengevaluasi Akhir

Mengevaluasi akhir dilakukan untuk mengetahui apakah testing hasil pengolahan data sesuai dengan yang diharapkan.

\subsection{Arsitektur Jaringan}

Arsitektur jaringan syaraf tiruan yang digunakan dapat dilihat sebagai berikut :

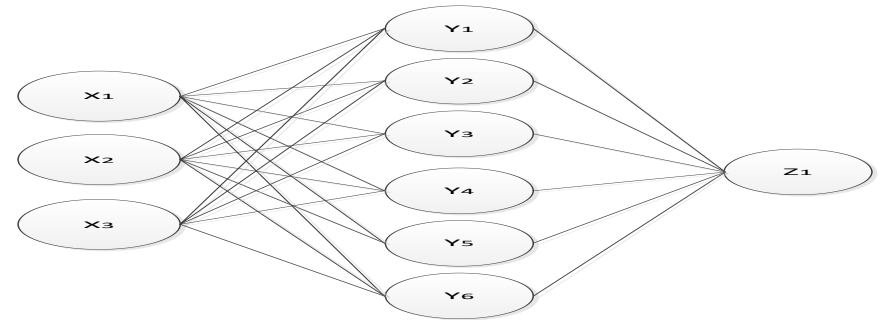

Gambar 2. Arsitektur Jaringan Syaraf Tiruan Yang Digunakan

Keterangan :

X1 - X3 : Data Masukan (Input Layer)

Y1 - Y6 : : Lapisan Tersembunyi (Hidden Layer)

Z1 : Hasil Keluaran (Output Layer)

Pola arsitektur jaringan yang digunakan untuk prediksi jumlah pelanggan PT. Telkom Akses area Sumbagut yaitu 3-N-1. Dimana 3 adalah node data input. 
Sedangkan jumlah hidden node N menggunakan aturan 'rule of thumb'. Pada penelitian ini menggunakan 6 hidden, serta 1 keluaran.

\subsection{Data Yang Digunakan}

Data yang digunakan dalam penelitian ini adalah Data Pelanggan PT. Telkom Akses Area Sumbagut tahun 2012-2017 (Tabel 1). Data pelatihan yang akan digunakan adalah 2012-2014 dengan target tahun 2015. Sedangkan data pengujian yang akan digunakan adalah data tahun 2014-2016 dengan target 2017.

\subsection{Normalisasi Data}

Sebelum diproses, data dinormalisasi terlebih dahulu dengan menggunakan fungsi sigmoid(tidak pernah mencapai 0 ataupun 1), maka tranformasi data dilakukan pada interval yang lebih kecil yaitu[0.1;0.9], ditunjukkan dengan persamaan (1) [17]-[30].

$x^{\prime}=\frac{0,8(x-a)}{b-a}+0,1$

Tabel 2. Data Pelatihan Awal (Tahun 2012-2014)/Target Tahun 2015

\begin{tabular}{|c|l|c|c|c|c|}
\hline No & Nama Kota & $\mathbf{2 0 1 2}$ & $\mathbf{2 0 1 3}$ & $\mathbf{2 0 1 4}$ & Target \\
\hline 1 & Pematangsiantar & 57 & 83 & 121 & 169 \\
\hline 2 & Rambung Merah & 12 & 34 & 67 & 98 \\
\hline 3 & Pematang raya & 19 & 42 & 84 & 133 \\
\hline 4 & Sidamanik & 6 & 26 & 58 & 81 \\
\hline 5 & Seribudolok & 4 & 19 & 34 & 58 \\
\hline 6 & Parapat & 26 & 55 & 90 & 134 \\
\hline 7 & Serbelawan & 16 & 33 & 69 & 90 \\
\hline 8 & Perdagangan & 8 & 24 & 55 & 81 \\
\hline 9 & Kisaran & 17 & 30 & 51 & 89 \\
\hline 10 & Tanjung Balai & 9 & 29 & 47 & 59 \\
\hline
\end{tabular}

Tabel 3. Data Pelatihan Setelah Normalisasi (2012-2014)/Target Tahun 2015

\begin{tabular}{|c|l|c|c|c|c|}
\hline No & Nama Kota & $\mathbf{2 0 1 2}$ & $\mathbf{2 0 1 3}$ & $\mathbf{2 0 1 4}$ & Target \\
\hline 1 & Pematangsiantar & 0,3602 & 0,4855 & 0,6687 & 0,9000 \\
\hline 2 & Rambung Merah & 0,1434 & 0,2494 & 0,4084 & 0,5578 \\
\hline 3 & Pematang raya & 0,1771 & 0,2880 & 0,4904 & 0,7265 \\
\hline 4 & Sidamanik & 0,1145 & 0,2108 & 0,3651 & 0,4759 \\
\hline 5 & Seribudolok & 0,1048 & 0,1771 & 0,2494 & 0,3651 \\
\hline 6 & Parapat & 0,2108 & 0,3506 & 0,5193 & 0,7313 \\
\hline 7 & Serbelawan & 0,1627 & 0,2446 & 0,4181 & 0,5193 \\
\hline 8 & Perdagangan & 0,1241 & 0,2012 & 0,3506 & 0,4759 \\
\hline 9 & Kisaran & 0,1675 & 0,2301 & 0,3313 & 0,5145 \\
\hline 10 & Tanjung Balai & 0,1289 & 0,2253 & 0,3120 & 0,3699 \\
\hline
\end{tabular}

Tabel 4. Data Pengujian Awal (Tahun 2014-2016)/Target Tahun 2017

\begin{tabular}{|c|l|c|c|c|c|}
\hline No & Nama Kota & $\mathbf{2 0 1 4}$ & $\mathbf{2 0 1 5}$ & $\mathbf{2 0 1 6}$ & Target \\
\hline 1 & Pematangsiantar & 121 & 169 & 197 & 257 \\
\hline 2 & Rambung Merah & 67 & 98 & 122 & 159 \\
\hline 3 & Pematang raya & 84 & 133 & 176 & 193 \\
\hline 4 & Sidamanik & 58 & 81 & 101 & 124 \\
\hline 5 & Seribudolok & 34 & 58 & 71 & 93 \\
\hline
\end{tabular}

Prediksi Jumlah Pelanggan PT. Telkom Dengan Backpropagation (Reza Muhammad Riansah) | 808 


\begin{tabular}{|c|l|c|c|c|c|}
\hline No & Nama Kota & $\mathbf{2 0 1 4}$ & $\mathbf{2 0 1 5}$ & $\mathbf{2 0 1 6}$ & Target \\
\hline 6 & Parapat & 90 & 134 & 180 & 221 \\
\hline 7 & Serbelawan & 69 & 90 & 122 & 155 \\
\hline 8 & Perdagangan & 55 & 81 & 99 & 117 \\
\hline 9 & Kisaran & 51 & 89 & 102 & 129 \\
\hline 10 & Tanjung Balai & 47 & 59 & 82 & 101 \\
\hline
\end{tabular}

Tabel 5. Data Pengujian Setelah Normalisasi(2014-2016)/Target Tahun 2017

\begin{tabular}{|c|l|c|c|c|c|}
\hline No & Nama Kota & $\mathbf{2 0 1 4}$ & $\mathbf{2 0 1 5}$ & $\mathbf{2 0 1 6}$ & Target \\
\hline 1 & Pematangsiantar & 0,4523 & 0,6103 & 0,7025 & 0,9000 \\
\hline 2 & Rambung Merah & 0,2745 & 0,3765 & 0,4556 & 0,5774 \\
\hline 3 & Pematang raya & 0,3305 & 0,4918 & 0,6333 & 0,6893 \\
\hline 4 & Sidamanik & 0,2449 & 0,3206 & 0,3864 & 0,4621 \\
\hline 5 & Seribudolok & 0,1658 & 0,2449 & 0,2877 & 0,3601 \\
\hline 6 & Parapat & 0,3502 & 0,4951 & 0,6465 & 0,7815 \\
\hline 7 & Serbelawan & 0,2811 & 0,3502 & 0,4556 & 0,5642 \\
\hline 8 & Perdagangan & 0,2350 & 0,3206 & 0,3798 & 0,4391 \\
\hline 9 & Kisaran & 0,2218 & 0,3469 & 0,3897 & 0,4786 \\
\hline 10 & Tanjung Balai & 0,2086 & 0,2481 & 0,3239 & 0,3864 \\
\hline
\end{tabular}

\section{HASIL DAN PEMBAHASAN}

\subsection{Analisis}

Sebelum pelatihan dilakukan, terlebih dahulu ditentukan nilai parameter yang diinginkan guna memperoleh hasil yang optimal. Parameter-parameter yang digunakan secara umum pada aplikasi Matlab untuk pelatihan dan pengujian dapat dilihat pada kode berikut :

$>>$ net $=$ newff(minmax(P),[Hidden,Target $],\left\{{ }^{\prime}\right.$ logsig',' 'purelin' $\}$,'traingd');

$>$ net.lw $\{1,1\}$;

$>>$ net.b $\{1\}$;

$>>$ net.lw $\{2,1\}$;

$>>$ net.b $\{2\}$;

$>>$ net.trainParam.epochs $=100000$;

$>>$ net.trainParam.goal $=0.001$;

$>>$ net.trainParam. $L r=0.01$;

$>>$ net.trainParam.show $=1000$;

$>$ net $=$ train $($ net, $\mathrm{P}, \mathrm{T})$

$>>[$ a,Pf,Af,e,Perf $]=\operatorname{sim}($ net, $\mathrm{P},[],[], T)$

\subsection{Hasil}

Penelitian ini menggunakan 5 arsitektur. Antara lain 3-10-1, 3-12-1, 3-14-1, 3-16-1, 3-18-1 dan 3-20-1. Dari ke 6 arsitektur ini, arsitektur terbaiknya yaitu 314-1 dengan tingkat akurasi 85\%. 


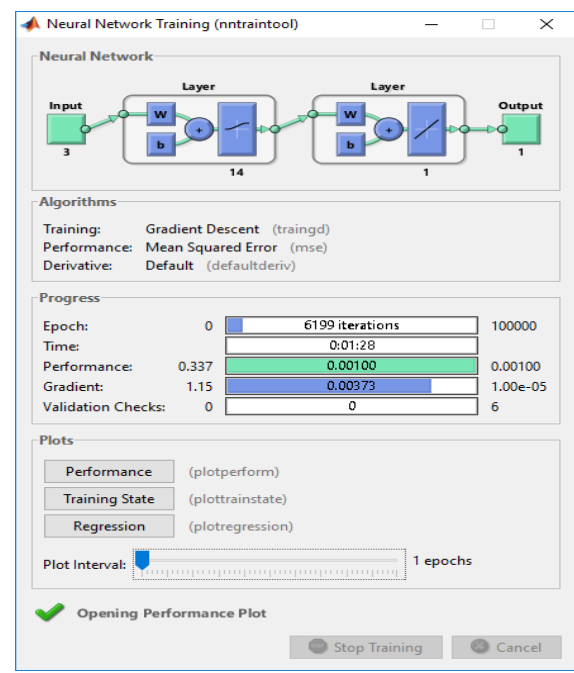

Gambar 3. Hasil Data Pelatihan Dengan Arsitektur 3-14-1

Dari gambar model arsitektur 3-14-1 diatas dapat dijelaskan bahwa Epoch yang terjadi sebesar 6199 dengan lama waktu 1 menit 28 detik.

\begin{tabular}{|c|c|c|c|c|c|c|c|c|c|c|c|}
\hline \multicolumn{6}{|c|}{ DATA PELATIHAN } & \multicolumn{6}{|c|}{ DATA PENGUJIAN } \\
\hline No & Pola & Target & Output & Error & SSE & Pola & Target & Output & Error & SSE & Hasil \\
\hline 1 & Pola & 0,90000 & 0,9084 & $-0,0084$ & 0,00007056 & Pola & 0,9000 & 1,0718 & $-0,1718$ & 0,02951524 & 1 \\
\hline 2 & Pola & 0,55783 & 0,5436 & 0,0142 & 0,00020253 & Pola & 0,5774 & 0,4769 & 0,1005 & 0,01009347 & 0 \\
\hline 3 & $\frac{2}{20 l a}$ & 0,72651 & 0,6697 & 0,0568 & 0,00322692 & $\frac{2}{\text { Pola }}$ & 0,6893 & 0,8016 & $-0,1123$ & 0,01261120 & 1 \\
\hline 4 & Pola & 0,47590 & 0,5653 & $-0,0894$ & 0,00799171 & Pola & 0,4621 & 0,5892 & $-0,1271$ & 0,01614426 & 1 \\
\hline 5 & $\frac{4}{\text { Pola }}$ & 0,36506 & 0,3111 & 0,0540 & 0,00291171 & $\frac{4}{\text { Pola }}$ & 0,3601 & 0,4773 & $-0,1172$ & 0.01373999 & 1 \\
\hline 6 & Pola & 0,73133 & 0,7603 & $-0,0290$ & 0,00083953 & Pola & 0,7815 & 0,8331 & $-0,0516$ & 0,00266447 & 1 \\
\hline 7 & Pola & 0,51928 & 0,5262 & $-0,0069$ & 0,00004793 & Pola & 0,5642 & 0,5510 & 0.0132 & 0,00017417 & 0 \\
\hline 8 & Pola & 0,47590 & 0,5018 & $-0,0259$ & 0,00067062 & Pola & 0,4391 & 0,5888 & $-0,1497$ & 0,02241169 & 1 \\
\hline 9 & Pola & 0,51446 & 0,4814 & 0,0331 & 0,00109282 & Pola & 0,4786 & 0,5236 & $-0,0450$ & 0,00202493 & 1 \\
\hline 10 & $\begin{array}{c}\text { Pola } \\
10\end{array}$ & 0,36988 & 0,3860 & $-0,0161$ & 0,00025987 & $\begin{array}{c}\text { Pola } \\
10\end{array}$ & 0,3864 & 0,7103 & $-0,3239$ & 0,10489841 & 1 \\
\hline
\end{tabular}

Gambar 4. Arsitektur JST Bacpropagation

Dari gambar diatas dapat dijelaskan bahwa 1 bernilai benar dan 0 bernilai salah.

Tabel 6. Hasil Akurasi Backpropagation

\begin{tabular}{|c|c|c|c|c|c|c|}
\hline NO & Arsitektur & \multicolumn{3}{|c|}{ Training } & \multicolumn{2}{c|}{ Testing } \\
\cline { 3 - 7 } & & Epoch & Waktu & MSE & MSE & Akurasi \\
\hline 1 & $3-10-1$ & 20746 & $05: 03$ & 0,00099983 & 0,01591401 & 59 \\
\hline 2 & $3-12-1$ & 27510 & $06: 23$ & 0,00100011 & 0,01282991 & 47 \\
\hline 3 & $3-14-1$ & 6199 & $01: 28$ & 0,02060619 & 0,01098654 & 85 \\
\hline 4 & $3-16-1$ & 17252 & $04: 01$ & 0,00099973 & 0,00382491 & 59 \\
\hline 5 & $3-18-1$ & 16280 & $03: 47$ & 0,00100016 & 0,02832844 & 79 \\
\hline 6 & $3-20-1$ & 64575 & $16: 14$ & 0,00100073 & 0,01759714 & 82 \\
\hline
\end{tabular}

Berikut adalah hasil prediksi 4 tahun kedepan dengan backpropagation (Tahun 2018-2021) seperti pada gambar 5. 


\begin{tabular}{|c|l|c|c|c|c|c|c|c|c|c|c|}
\hline No & Nama Kota & \multicolumn{9}{|c|}{ Tahun } & \multicolumn{9}{|c|}{} & \\
\cline { 3 - 12 } & & $\mathbf{2 0 1 2}$ & $\mathbf{2 0 1 3}$ & $\mathbf{2 0 1 4}$ & $\mathbf{2 0 1 5}$ & $\mathbf{2 0 1 6}$ & $\mathbf{2 0 1 7}$ & $\mathbf{2 0 1 8}$ & $\mathbf{2 0 1 9}$ & $\mathbf{2 0 2 0}$ & $\mathbf{2 0 2 1}$ \\
\hline 1 & $\begin{array}{l}\text { Pematang } \\
\text { siantar }\end{array}$ & 57 & 83 & 121 & 169 & 197 & 257 & 261 & 275 & 293 & 327 \\
\hline 2 & $\begin{array}{l}\text { Rambung } \\
\text { Merah }\end{array}$ & 12 & 34 & 67 & 98 & 122 & 159 & 157 & 159 & 195 & 253 \\
\hline 3 & $\begin{array}{l}\text { Pematang } \\
\text { raya }\end{array}$ & 19 & 42 & 84 & 133 & 176 & 193 & 212 & 208 & 219 & 245 \\
\hline 4 & Sidamanik & 6 & 26 & 58 & 81 & 101 & 124 & 150 & 176 & 206 & 254 \\
\hline 5 & Seribudolok & 4 & 19 & 34 & 58 & 71 & 93 & 101 & 127 & 167 & 224 \\
\hline 6 & Parapat & 26 & 55 & 90 & 134 & 180 & 221 & 222 & 228 & 254 & 280 \\
\hline 7 & Serbelawan & 16 & 33 & 69 & 90 & 122 & 155 & 159 & 166 & 195 & 250 \\
\hline 8 & Perdagangan & 8 & 24 & 55 & 81 & 99 & 117 & 145 & 177 & 206 & 253 \\
\hline 9 & Kisaran & 17 & 30 & 51 & 89 & 102 & 129 & 139 & 176 & 216 & 249 \\
\hline 10 & Tanjung Balai & 9 & 29 & 47 & 59 & 82 & 101 & 117 & 139 & 191 & 244 \\
\hline
\end{tabular}

Gambar 5. Hasil Prediksi 4 Tahun Kedepan Dengan Backpropagation (2018-2021)

\section{KESIMPULAN}

Kesimpulan yang dapat diambil dari penelitian ini antara lain :

a. Dengan Model arsitektur 3-14-1, dapat melakukan prediksi dengan akurasi $85 \%$.

b. Model jaringan serta parameter yang digunakan sangat mempengaruhi tingkat akurasi.

c. Pemilihan model arsitektur terbaik sangat berpengaruh untuk mendapatkan tingkat keakurasian dan hasil prediksi yang optimal.

\section{DAFTAR PUSTAKA}

[1] N. Fajira, "Analisis Kepuasan Pelanggan Terhadap Kualitas Pelayanan Pada Kentucky Fried Chicken Cabang Palembang Square Mall,” 2014.

[2] Y. Sari, "Jaringan Syaraf Tiruan Backpropagation Untuk Memprediksi Luas Area Serangga Hama Pada Tanaman Bawang," 2016.

[3] R. W. Purnamasari, "Implementasi Jaringan Syaraf Tiruan Backpropagation Sebagai Sistem Deteksi Penyakit Tuberculosis ( TBC )," 2013.

[4] I. Muzakkir, A. Syukur, and I. N. Dewi, "Peningkatan Akurasi Algoritma Backpropagation Dengan Seleksi Fitur Particle Swarm Optimization Dalam Prediksi Pelanggan Telekomunikasi Yang Hilang," Jurnal Pseudocode, vol. 1, no. 1, pp. 1-10, 2014.

[5] A. Wanto and A. P. Windarto, "Analisis Prediksi Indeks Harga Konsumen Berdasarkan Kelompok Kesehatan Dengan Menggunakan Metode Backpropagation," Jurnal \& Penelitian Teknik Informatika Sinkron, vol. 2, no. 2, pp. 37-44, 2017.

[6] A. Wanto, A. P. Windarto, D. Hartama, and I. Parlina, "Use of Binary Sigmoid Function And Linear Identity In Artificial Neural Networks For Forecasting Population Density," International Journal of Information System \& Technology, vol. 1, no. 1, pp. 43-54, 2017.

[7] A. Wanto, M. Zarlis, Sawaluddin, and D. Hartama, "Analysis of Artificial Neural Network Backpropagation Using Conjugate Gradient Fletcher Reeves in the Predicting Process," Journal of Physics: Conference Series, vol. 930, no. 1, pp. 1-7, 2017.

[8] S. P. Siregar and A. Wanto, "Analysis of Artificial Neural Network Accuracy Using Backpropagation Algorithm In Predicting Process (Forecasting)," International Journal of Information System \& Technology, vol. 1, no. 1, pp. 34-42, 2017.

[9] J. R. Saragih, M. Billy, S. Saragih, and A. Wanto, "Analisis Algoritma Backpropagation Dalam Prediksi Nilai Ekspor (Juta USD),” Jurnal Pendidikan Teknologi dan Kejuruan, vol. 15, no. 2, pp. 254-264, 2018.

[10] E. Hartato, D. Sitorus, and A. Wanto, "Analisis Jaringan Saraf Tiruan Untuk Prediksi Luas Panen Biofarmaka di Indonesia," Jurnal semanTIK, vol. 4, no. 1, pp. 49-56, 2018.

[11] S. Setti and A. Wanto, "Analysis of Backpropagation Algorithm in Predicting the Most Number of Internet Users in the World," JOIN (Jurnal Online Informatika), vol. 3, no. 2, pp. 110-115, 2018.

[12] R. E. Pranata, S. P. Sinaga, and A. Wanto, "Estimasi Wisatawan Mancanegara Yang Datang ke 
Sumatera Utara Menggunakan Jaringan Saraf," Jurnal semanTIK, vol. 4, no. 1, pp. 97-102, 2018.

[13] A. A. Fardhani, D. Insani, N. Simanjuntak, and A. Wanto, "Prediksi Harga Eceran Beras Di Pasar Tradisional Di 33 Kota Di Indonesia Menggunakan Algoritma Backpropagation," Jurnal Infomedia, vol. 3, no. 1, pp. 25-30, 2018.

[14] J. Wahyuni, Y. W. Paranthy, and A. Wanto, "Analisis Jaringan Saraf Dalam Estimasi Tingkat Pengangguran Terbuka Penduduk Sumatera Utara,” Jurnal Infomedia, vol. 3, no. 1, pp. 1824, 2018.

[15] S. Riyadi, "Pengaruh Gaya Kepemimpinan Terhadap Kedisiplinan Kerja Karyawan PT Telkom Akses (PTTA) Area Lembong Bandung," 2016.

[16] A. Wanto and A. P. Windarto, "Analisis Prediksi Indeks Harga Konsumen Berdasarkan Kelompok Kesehatan Dengan Menggunakan Metode Backpropagation," Jurnal \& Penelitian Teknik Informatika Sinkron, vol. 2, no. 2, pp. 37-43, Oct. 2017.

[17] A. Wanto et al., "Levenberg-Marquardt Algorithm Combined with Bipolar Sigmoid Function to Measure Open Unemployment Rate in Indonesia," in Conference Paper, 2018, pp. 1-7.

[18] I. A. R. Simbolon, F. Yatussa'ada, and A. Wanto, "Penerapan Algoritma Backpropagation dalam Memprediksi Persentase Penduduk Buta Huruf di Indonesia," Jurnal Informatika Upgris, vol. 4, no. 2, pp. 163-169, 2018.

[19] S. P. Siregar, A. Wanto, and Z. M. Nasution, "Analisis Akurasi Arsitektur JST Berdasarkan Jumlah Penduduk Pada Kabupaten / Kota di Sumatera Utara," in Seminar Nasional Sains \& Teknologi Informasi (SENSASI), 2018, pp. 526-536.

[20] A. Wanto, “Optimasi Prediksi Dengan Algoritma Backpropagation Dan Conjugate Gradient Beale-Powell Restarts," Jurnal Teknologi dan Sistem Informasi, vol. 3, no. 3, pp. 370-380, Jan. 2018.

[21] B. K. Sihotang and A. Wanto, "Analisis Jaringan Syaraf Tiruan Dalam Memprediksi Jumlah Tamu Pada Hotel Non Bintang," Jurnal Teknologi Informasi Techno, vol. 17, no. 4, pp. 333346, 2018.

[22] M. A. P. Hutabarat, M. Julham, and A. Wanto, "Penerapan Algoritma Backpropagation Dalam Memprediksi Produksi Tanaman Padi Sawah Menurut Kabupaten/Kota di Sumatera Utara," Jurnal semanTIK, vol. 4, no. 1, pp. 77-86, 2018.

[23] Y. Andriani, H. Silitonga, and A. Wanto, "Analisis Jaringan Syaraf Tiruan untuk prediksi volume ekspor dan impor migas di Indonesia," Register - Jurnal Ilmiah Teknologi Sistem Informasi, vol. 4, no. 1, pp. 30-40, 2018.

[24] A. Wanto, "Penerapan Jaringan Saraf Tiruan Dalam Memprediksi Jumlah Kemiskinan Pada Kabupaten/Kota Di Provinsi Riau," Kumpulan jurnaL Ilmu Komputer (KLIK), vol. 5, no. 1, pp. 61-74, 2018.

[25] I. S. Purba and A. Wanto, "Prediksi Jumlah Nilai Impor Sumatera Utara Menurut Negara Asal Menggunakan Algoritma Backpropagation," Jurnal Teknologi Informasi Techno, vol. 17, no. 3, pp. 302-311, 2018.

[26] A. Wanto, "Prediksi Angka Partisipasi Sekolah dengan Fungsi Pelatihan Gradient Descent With Momentum \& Adaptive LR," Jurnal Ilmu Komputer dan Informatika (ALGORITMA), vol. 3, no. 1, pp. 9-20, 2019.

[27] N. Nasution, A. Zamsuri, L. Lisnawita, and A. Wanto, "Polak-Ribiere updates analysis with binary and linear function in determining coffee exports in Indonesia," IOP Conference Series: Materials Science and Engineering, vol. 420, no. 12089, pp. 1-9, 2018.

[28] A. Wanto, "Prediksi Produktivitas Jagung Indonesia Tahun 2019-2020 Sebagai Upaya Antisipasi Impor Menggunakan Jaringan Saraf Tiruan Backpropagation," SINTECH (Science and Information Technology), vol. 1, no. 1, pp. 53-62, 2019.

[29] B. Febriadi, Z. Zamzami, Y. Yunefri, and A. Wanto, "Bipolar function in backpropagation algorithm in predicting Indonesia's coal exports by major destination countries," IOP Conference Series: Materials Science and Engineering, vol. 420, no. 12089, pp. 1-9, 2018.

[30] A. Wanto et al., "Analysis of Standard Gradient Descent with GD Momentum And Adaptive LR for SPR Prediction,” 2018, pp. 1-9. 